\title{
DOWNHOLE REACTIVE POWER COMPENSATION
}

\author{
• • опырин, · · орд н, · • мирнов \\ V. A. Kopyrin, V. A. Iordan, O. V. Smirnov
}

юменский госуд рственный нефтег зовый университет, г. юмень

лючевые слов : внутрискв жинный компенс тор; компенс тор ре ктивной мощности;
погружной электродвиг тель; электрический к бель

Key words: downhole compensator; reactive capacity compensator; submersible electric motor; electrical cable

нефтег зодобыв ющей отр сли при эксплу т ции нефтяных скв жин н ибольшее р спростр нение получили уст новки погружных центробежных н сосов ( ). ми осн щено свыше $65 \%$ фонд нефтедобыв ющих скв жин [1, 2]. месторождениях « зпромнефть- оябрьскнефтег з» из 4000 скв жин более $92 \%$ оборудов ны [3].

к честве привод к уст новк м электроцентробежных н сосов используются погружные синхронные трехф зные электродвиг тели ( ). пр вление и з щит электродвиг телей погружных центробежных н сосов осуществляется с помощью комплекс оборудов ния, смонтиров нного н тр нсформ торной подст нции или ст нции упр вления скв жин. оэффициент мощности уст новок с погружными электроцентробежными н сос ми, определяемый в основном $\cos \varphi$, н ходится в предел х 0,7-0,85 при номин льной н грузке и может сниж ться до 0,6-0,75 при недогрузк х, что приводит увеличению потребляемой ре ктивной мощности и потерям ктивной мощности в к беле [4].

дним из известных способов компенс ции ре ктивной мощности является уст новк п р ллельно с н грузкой низковольтных косинусных конденс торов в сост ве оборудов ния ст нций упр вления - дн ко подобн я схем компоновки оборудов ния имеет существенный недост ток - потребитель ре ктивной мощности (погружной электродвиг тель) может н ходиться н уд ленном р сстоянии от источник (до 3000 м), что приводит к увеличению потерь мощности по длине пит ющего погружного к беля [5]. змещение компенсирующего устройств непосредственно внутри корпус или в непосредственной близости от него позволило бы исключить этот недост ток.

н стоящее время вопрос об энергетической эффективности, связ нной с компенс цией ре ктивной мощности непосредственно внутри скв жины, не прор б тыв лся ввиду сложности ре лиз ции т ких устройств. ежду тем тем внутрискв жинной компенс ции ре ктивной мощности ст новится кту льной. 2013 году фонд « колково» в П ртнерстве с « - »и « зпром нефть» объявил конкурс н проведение по теме « зр ботк внутрискв жинных компенс торов ре ктивной мощности» с выделением гр нт в р змере 5000000 руб.

д нной ст тье про н лизиров н предл г емый способ внутрискв жинной компенс ции ре ктивной мощности н примере с погружным электродвиг телем - 90-117 5. р метры электродвиг теля приведены в т бл. 1. 
ехнические п р метры - 90-117 5

\begin{tabular}{|c|c|c|c|c|c|c|}
\hline $\begin{array}{c}\text { ип } \\
\text { двиг теля }\end{array}$ & $\begin{array}{c}\text { ощность } \\
\text { при } 50 \text { ц, } \\
\text { т }\end{array}$ & $\begin{array}{l}\text { омин льное } \\
\text { н пряжение } \\
\text { при } 50 \text { ц, }\end{array}$ & $\begin{array}{l}\text { омин льный } \\
\text { ток, }\end{array}$ & $\cos \varphi$ & & $\begin{array}{c}\text { кольжение, } \\
\text { \% }\end{array}$ \\
\hline $\begin{array}{c}-90-117 \\
5\end{array}$ & 90 & 1800 & 44 & 0,84 & 0,84 & 5 \\
\hline
\end{tabular}

ит ние и упр вление ( ) мошностью $160 \mathrm{~K}$ ние н выходе 1800 . ит ние 500 м. ехнические п р метры к беля приведены в т бл. 2.

ехнические п р метры к беля

\begin{tabular}{|c|c|c|c|c|c|}
\hline $\begin{array}{c}\text { рк } \\
\text { к беля }\end{array}$ & $\begin{array}{c}\text { исло } \\
\text { и сечение } \\
\text { токопроводящих } \\
\text { жил, мм }{ }^{2}\end{array}$ & $\begin{array}{c}\text { лительно } \\
\text { допустимый } \\
\text { ток } \\
\text { при } 80^{0},\end{array}$ & $\begin{array}{c}\text { огонное } \\
\text { ктивное } \\
\text { сопротивление } \\
\text { проводник } \\
\text { при } 20^{\circ}, \quad \text { м/км }\end{array}$ & $\begin{array}{c}\text { огонное } \\
\text { индуктивное } \\
\text { сопротивление } \\
\text { проводник } \\
\text { м/км }\end{array}$ & $\begin{array}{c}\text { мкость } \\
\text { к беля, } \\
\text { мк /км }\end{array}$ \\
\hline $903 \times 16$ & $3 \times 16$ & 44 & 1,15 & 0,0757 & 0,1 \\
\hline
\end{tabular}

рименяемый в н стоящее время способ компенс ции ре ктивной мощности требует уст новки компенсирующего устройств мощностью 75 к $\quad$ н н для поддерж ния норм льного $\cos \varphi=0,95$. к к к н ходится н р сстоянии 2500 м от, предл г ется перенести уст новку компенс ции ре ктивной мощности ( ) внутрь скв жины непосредственно к

рис. 1 приведен р зр бот нн я в среде Matlab/Simylink модель уч стк электросн бжения от тр нсформ торной подст нции до [6].

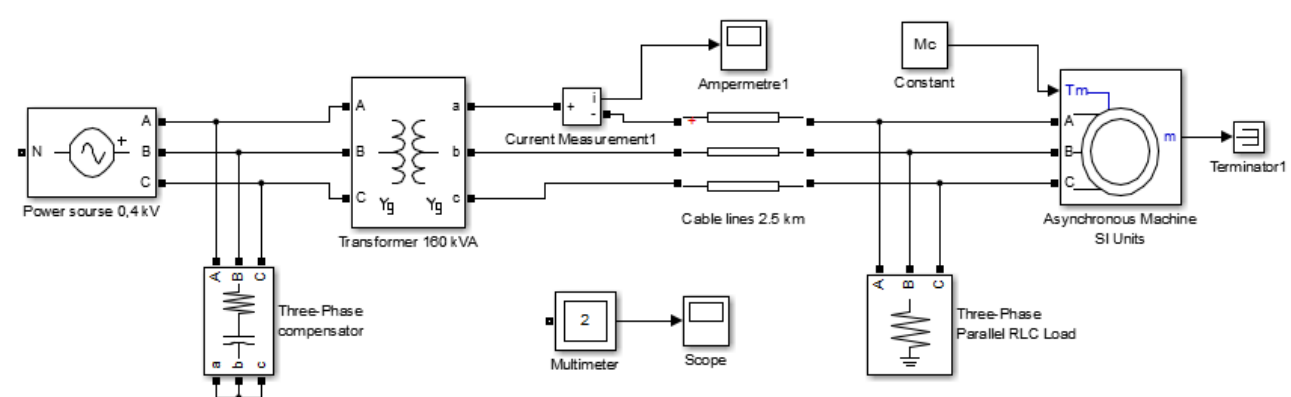

a)

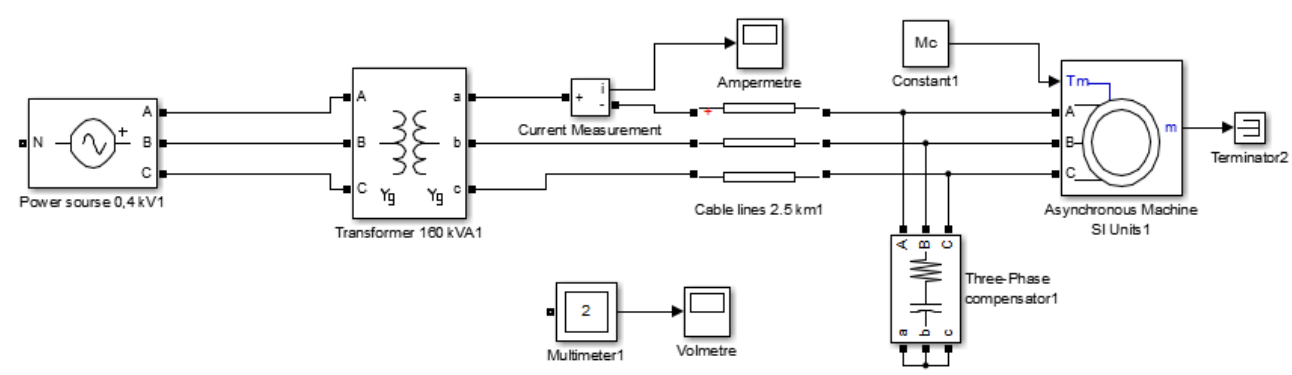

б)

ис. 1. хем модели уч стк электросн бжения от тр нсформ торной подст нции: ) компенсирующее устройство до пит ющего тр нсформ тор ;

б) компенсирующее устройство перед погружным электродвиг телем 
ходе моделиров ния получены гр фики н пряжения н выходе с источник пит ния $\mathrm{U}_{\text {ист }}$ и в конце пит ющей к бельной линии $\mathrm{U}_{\text {вых }}$, при компенс ции ре ктивной мощности до пит ющего тр нсформ тор (рис. 2 ), перед (рис. 2 б). ри моделиров нии р бот л с $\cos \varphi=0,72$.

з н лиз гр фиков рис. 2 следует, что при компенс ции ре ктивной мощности по первому способу (см. рис. 1 ), действующее н пряжение в конце сост вило $\mathrm{U}_{\text {вых }}=1633$, п дение н пряжения $\mathrm{U}=167$, что н 9,3\% меньше н пряжения источник пит ния.
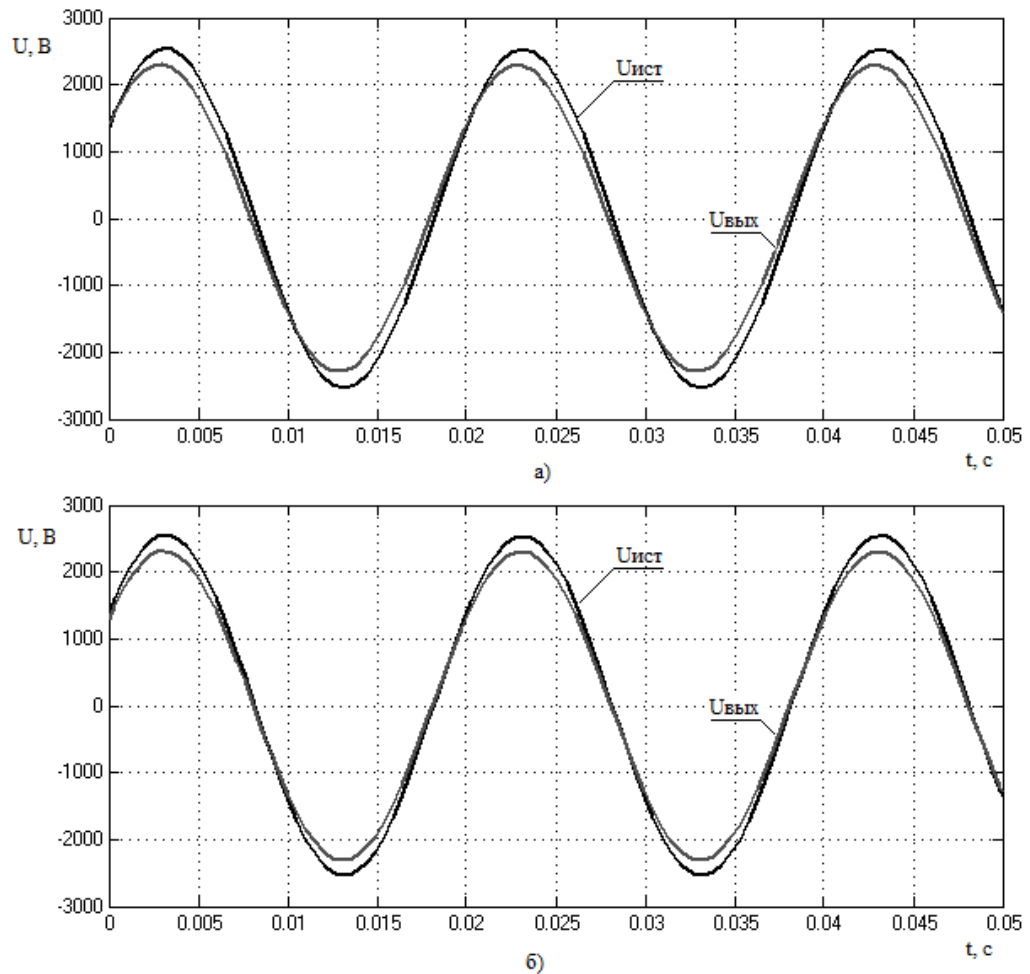

ис. 2. р фики мплитудных зн чений н пряжений н выходе с источник

пит ния $\boldsymbol{U}_{\text {ист }}$ и в конце пит ющей к бельной линии $\boldsymbol{U}_{\text {вых }}$ : ) компенс ция ре ктивной мощности до пит ющего тр нсформ тор ; б) компенс ция ре ктивной мощности перед погружным электродвиг телем

ействующее зн чение ф зного ток для существующего способ компенс ции рективной мощности $\mathrm{I}_{1 \phi}=45,3$ (рис. 3 ).

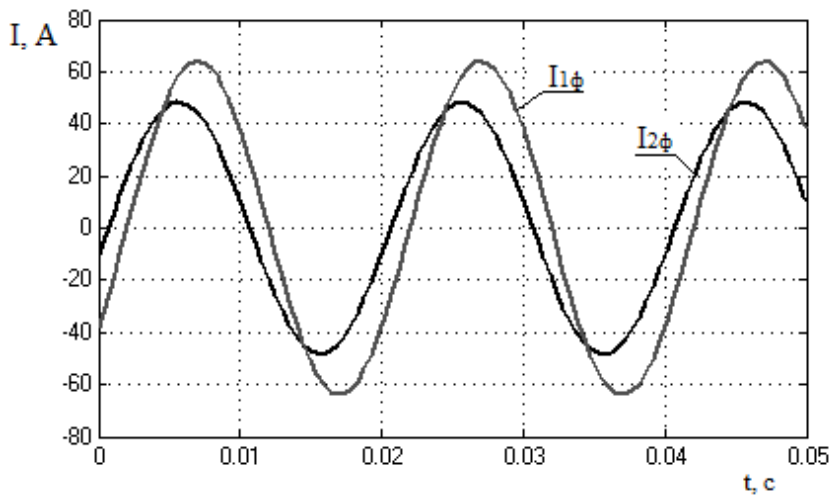

ис. 3. р фики мплитудных зн чений ф зных токов для двух способов компенс ции ре ктивной мощности 
отери ктивной мощности в к бельной линии определяются по формуле

$$
\Delta P=3 \cdot I_{\phi}^{2} \cdot R_{\phi}
$$

где $\Delta P$ - потери ктивной мощности в $\quad, \quad$ т; $I_{\phi}-$ действующее зн чение ф зного ток , ; $R_{\phi}-$ ктивное сопротивление токопроводящей жилы $\quad$, м.

ким обр зом, потери ктивной мощности в для существующего способ (см. рис. 1 ):

$$
\Delta P_{1}=3 \cdot 45,3^{2} \cdot 2,875=14082 \quad \text { т. }
$$

ри уст новке

предл г емым способом (см. рис. 1 б) действующее н пряжение в конце сост вило $\mathrm{U}_{\text {вых }}=1702$, п дение н пряжения $\mathrm{U}=98$, что н $5,4 \%$ меньше н пряжения источник пит ния. ействующее зн чение ф зного ток $\mathrm{I}_{2 \phi}=34,2$, коэффициент мощности $\cos f=0,95$ (см. рис. 3). отери ктивной мощности в к бельной линии для предл г емого способ определяются по формуле (1)

$$
\Delta P_{2}=3 \cdot 34,2^{2} \cdot 2,875=10060 \quad \text { т. }
$$

олученные в ходе р счетов д нные при компенс ции ре ктивной мощности двумя способ ми сведены в т бл. 3.

блии 3

счетные д нные цепи при двух способ х компенс ции ре ктивной мощности

\begin{tabular}{|c|c|c|c|c|c|}
\hline $\begin{array}{c}\text { пособ } \\
\text { уст новки }\end{array}$ & $\begin{array}{c}\text { пряжение в } \\
\text { н ч ле }\end{array}$ & $\begin{array}{c}\text { пряжение в } \\
\text { конце }\end{array}$ & $\begin{array}{c}\text { ействующее } \\
\text { зн чение ток , І }\end{array}$ & $\begin{array}{c}\text { отери ктивной } \\
\text { мощности } \\
\text { в , к т }\end{array}$ & $\begin{array}{c}\text { оля } \\
\text { потерь, \% }\end{array}$ \\
\hline 1 & 1800 & 1633 & 45,3 & 14,08 & 11 \\
\hline 2 & 1800 & 1702 & 34,2 & 10,06 & 7,5 \\
\hline
\end{tabular}

з т бл. 3 видно, что доля потерь в от мощности, потребляемой $\quad$ для первого способ сост вил $11 \%$, для второго $-7,5 \%$.

ким обр зом, предложенный способ компенс ции ре ктивной мощности позволяет уменьшить потери ктивной мощности в н $31,8 \%$ или 4 к т. зр бот нн я в cреде Matlab/Simylink модель уч стк энергопит ния от позволяет определить величину потерь ктивной мощности в к бельной линии, т кже действующее н пряжение н 3 жим х и действующее зн чение ф зного ток . дн ко для ре лиз ции способ необходимо провести исследов ние н опытном обр зце.

писок литер туры

1. дольник . . овершенствов ние электроцентробежной н сосной уст новки для скв жин с высокой пл стовой темпер турой: втореф. дисс. к. т. н.: 05.02.13/ дольник ергей вгеньевич; [ есто з щиты: фим. гос. нефтяной техн. ун-т]. $-\phi, 2008 .-.6$.

2. елусенко . ., в рц . ., еликий . ., ршов . ., ризов . . овые технологии и современное оборудов ние в электроэнергетике нефтег зовой промышленности..- .2 « едр - изнесцентр», 2007. - . 404.

3. нуфриев . ., огорелов . . пыт эксплу т ции - в условиях повышенного содерж ния мехпримесей // роизводственно-технический нефтег зовый журн л « нженерн я пр ктик ». - 2010. - № 2. - . 66-72.

4. еньшов . ., ршов . ., ризов . . лектротехнические уст новки и комплексы в нефтег зовой промышленности: чеб. для вузов. -..$\quad$ едр , 2000. - . 293.

5. т. №145053 оссийск я едер ция, G05F1/70, Н02J3/18. нутрискв жинный компенс тор ре ктивной мощности/ опырин . ., р . ., ортнягин . ., мирнов . . - № 2014116437/07; з явл. 23.04.2014; опубл. 10.09.2014.

6. ерных . . оделиров ние электротехнических устройств в MATLAB. Sim Power Systems и Simulink. - . pecc, 2007. $-288 \mathrm{c}$.

Сведения об втор $x$

опырин я димир н тольевич, спир нт кфедры "лектроэнергетик », юменский госуд рственный нефтег зовый университет, г. юмень, тел. 89129942447, e-mail: kopyrinva@gmail.com

орд н ит лий лекс ндрович, спир нтк федры « лектроэнергетик », юменский госуд рственный нефтег зовый университет, г. юмень, тел. 89058220312,e-mail: vaiordan@gmail.com
Information about the authors

Kopyrin V. A., postgraduate of the chair «Electroenergetics», Tyumen State Oil and Gas University, phone: 8129942447,e-mail: kopyrinva@gmail.com

Iordan $\boldsymbol{V}$. A., postgraduate of the chair «Electroenergetics», Tyumen State Oil and Gas University, phone: 89058220312,e-mail: vaiordan@gmail.com 
мирнов лег л димирович, Ә. к федры "лектроэнергетик », юменский госуд рственный нефтег зовый университет, г. юмень, тел 89129275192,e-mail: oleg_smirnov_1940@mail.ru
Smirnov O. V., Doctor of Science in Engineering, professor of the chair "Electroenergetics», Tyumen State Oil and Gas University, phone: 89129275192, e-mail. oleg_smirnov_1940@mail.ru 